\title{
Integrating Open-Ended Design in a Science and Mathematics Based Engineering Program
}

\author{
Paul Winkelman \\ Department of Mechanical Engineering, University of British Columbia \\ pwinkel@mech.ubc.ca
}

\begin{abstract}
With curricula based largely on science and mathematics, engineering programs promote the ideal of striving for that one predetermined, correct answer. Design, being open-ended, cannot promote that single, correct answer. Thus, the paradigm of design and that of science and mathematics are not the same, presenting pedagogical challenges. The metaphor of the podium is used to highlight these challenges and suggest ways that engineering curricula might be reconstructed to honour design as well as science and mathematics. Case studies, consisting of interviews and focus groups of prospective and first-year engineering students, as well as high school teachers, provide the data for the research.
\end{abstract}

Keywords: design education, creativity, science education

\section{Introduction}

Science and mathematics have been the mainstay of engineering programs for many years. Its beginning can perhaps be traced back to Laplace who, around 200 years ago, sought to turn French engineering students into scientists [1]. The early engineering schools in the U.S. adopted the French model, preferring it to the more apprenticeship approach of the British [2]. Amos Eaton, who ran the then new Rensselaer school from 1824 to 1842 , promoted science within his engineering programs, putting forward five rules of education. Three of these rules make explicit reference to science [3]. When engineering schools began to grow in Canada, they were modelled after the U.S. schools [2]. Canadian institutions have generally continued to follow this tradition to this day.

As highly respected fields in their own rights, engineers looked to science and mathematics to legitimize their activities. Engineers saw science and mathematics as reducing ambiguity, affording a sense of correctness, that trial and error alone could not. Based on the logic and objectivity that science and mathematics afford, their products would be safe, reliable and function according to specifications. Equally importantly, engineers would be respected professionals.
As future professionals, students are impressed with the importance of science and mathematics for "as other disciplines become more scientific, and as the use of computers calls increasingly for logical data preparation, so designing, too, must become more logical, more sequential, more transparent, and more open to correction" $[4$, p. 10]. The drive to be both scientific and logical is encapsulated in the idealized form of the engineering problem-solution set, where only one answer is possible for a given problem and one arrives at that answer using mathematical formulas. When faced with new problems, they measure it against this exemplar model. If the new problem cannot be mapped to the exemplar, it may be considered uninteresting, irrelevant or unworthy of their talents. A case in point, perhaps, is the incident of 30 engineering students at Carleton University who plagiarized on their assignments [5]. It is ironic that they chose to do so in an ethics course. Not only did they flagrantly disregard university regulations, but they showed contempt for the very contents of the course itself.

If we turn our attention from science and mathematics to design in engineering, we find a very different story. It is only in the last 10 years or so that design has become a staple of engineering programs. Although it may be argued that design has been a part of engineering programs for a good many years, 
embedded in the science- and mathematics-based courses, its inclusion as a topic worthy of deliberate, directed study is quite recent. What is distinctive about this newer concept of design can perhaps be summed up by the Canadian Engineering Accreditation Board's (CEAB) [6] use of the word "significant" (p. 12). One might suppose that the peppering of traditional courses with incidental design issues does not result in a "significant experience".

In addition to being "significant", the CEAB also stipulates that the design experience be "open-ended". The open-endedness constitutes a marked departure from the traditional engineering curriculum. An openended experience implies a sizable amount of uncertainty, a problem where there is no predetermined answer. With the answer undetermined, there is no way of predicting where the solution search will take the designers. Boundaries become blurred, and design adopts a multidisciplinary approach where learning is carried out with teams rather than individuals.

The contrast between the paradigm of science and mathematics and the design paradigm is significant, for the pedagogical challenges it presents are many. Instructors accustomed to impressing on students the importance of arriving at the correct answer must now encourage students to develop their own unique solutions. The reins that kept the students from straying to far from the ideals of sciences and mathematics must now be loosened. The unexpected answer, previously assumed to be incorrect, may now become the exemplar.

\section{Objectives}

The objective of this research is to explore the differences between the two paradigms of science/mathematics and design, and point to some of the resulting pedagogical challenges. A better understanding of these challenges will facilitate the on-going development of engineering curricula that honour both paradigms without compromising the students' learning or experience.

\section{Research Approach}

The underlying assumption of this research is that engineering espouses certain kinds of knowledge while tending to dismiss other kinds of knowledge. The engineering curriculum thus teaches students which kinds of knowledge count and which do not. Coming from a different paradigm, design suggests a re-count. This research explores these differences and examines their implications by drawing on case study data superimposed on a conceptual frame.

\subsection{Conceptual Frame}

The issues surrounding science, mathematics and design in engineering will be explored using the metaphor of the podium. The inspiration comes from the work of Bell [7] who uses this metaphor to characterize and challenge the dominant values of success at universities, values not necessarily shared by all university faculty members.

The podium represents a value that is statusconscious. It reflects the belief in a hierarchical structure. At the podium stand those who are deemed successful, the achievers, and the winners in some kind of game. Below, surrounding the podium, are the teeming masses who have failed, the underachievers, those who have lost the game. Those privileged few at the podium stand head and shoulders above the masses below, distancing themselves from the indistinguishable individuals of the masses. The privileged few at the podium are there because they deserve to be.

The alternative view recognizes that those that stand on the podium are seldom there as a result of their own individual efforts. More often than not, they receive the help and support of others along the way. The podium risks neglecting the real contributions of others. The alternative view seeks to remove the podium, such that all stand at the same level and mix together. It promotes the idea that we are all interconnected and inter-dependent. It replaces competition with cooperation and mutual support.

Closely related to the podium metaphor is the concept of othering [8]. The idea of othering refers to the creation of an "us-them" dichotomy. The "us" is placed in a positive light, the "them", in a negative one. The "us" is seen as superior, and the "them" as inferior or deficient [9]. In terms of the podium metaphor, those that stand on the podium are defined as "us" and those that stand below, around the podium, are "them". The podium maintains a distance between the "us" and the "them". By removing the podium, the distancing is removed, along with the illusion it allows, as the "us" comes face to face with the "them", face to face with their prejudices.

\subsection{Research Method}

The data used for the study were collected through a series of case studies, according to some of the recommendations of Yin [10]. The case studies 
consisted of interviews and focus groups. The participants consisted of first-year engineering students (9 participants), Grade 12 high school students (4 participants) and high school teachers (4 participants). The engineering students were interviewed during the final weeks of the 2003 Winter semester at a large Canadian university; the high school students and teachers a few weeks later at a nearby school.

Interviews consisted of an interviewer (researcher) talking to a single interviewee one-on-one. Focus groups consisted of a researcher and two or more students. The type of study, i.e., focus group or interview, depended on the number of participants who attended a given session. If a single student showed up, an interview was conducted; if more than one, a focus group. As participation was strictly voluntary, the type of study could not be determined ahead of time.

With the one-on-one interview, the onus often falls largely on the researcher to maintain the conversation. This is particularly true if the interviewee is slow to offer unsolicited responses. Thus, the researchers must always have questions prepared ahead of time. This puts the researcher in the driver's seat, providing the opportunity to obtain answers that are fairly well directed at the research questions. At the same time, however, the genuineness of the responses is brought into question as the participant may be supplying an answer he or she feels the researcher is looking for, or interpret the question in ways that were unintended by the researcher. Hence, a good interview often requires questions that are carefully chosen and worded before the interview.

Focus groups attempt to address some of these concerns. The idea behind the focus group is that, by having several participants in the same discussion, synergy is produced [11]. Students react to and build upon each other's comments, leading to lively discussions. The dynamics may be such that the researcher spends his or her time listening rather than asking questions, being led rather than guiding the direction of the discussion. The expertise of the researcher shifts from creating good questions prior to the interview, to interpreting the data during and after the interview. The limited interference on the part of the researcher means that some of the research questions may be left unanswered. However, those comments that are made are much more likely to be genuine responses. In this setting there is also a greater chance that the participants will bring bring topics to the discussion that may be outside the initial research area, yet of significant interest. These comments may lead to new, fruitful research directions. Compared to the one-on-one interview, the benefits of the focus group tend to outweigh the drawbacks, and was therefore the preferred form of study.

Ethics approval was obtained from the university. Additional approval was necessary before studies could be conducted in high schools. Prior to the sessions, the researcher met informally with potential participants and outlined the research approach and objectives. It was made clear to the students that their participation was strictly voluntary and that they could withdraw from the study at any time for any reason. If they showed interest, they were each handed a consent form which they were expected to read and sign before attending a session. The consent form basically reiterated what the researcher had presented orally. High school students needed an additional consent form signed by a legal guardian before they could participate.

All sessions were audiotaped and transcribed. To help ensure anonymity, neither the tapes nor the transcribed materials made reference to the real names of the participants.

The collected data were reviewed and analysed. The analysis was largely interpretive and consisted of looking for themes, patterns or metaphors. These were examined to reveal the beliefs, attitudes and values of the students or the students' perceptions of the values and beliefs of those administering the engineering program. These themes may operate between groups or individuals, or they may be confined to a particular individual. As these are case studies, findings are not generalized to include all engineering students. However, some values expressed by the participants may be shared by other students who have not been interviewed. The research is intended to suggest a range of possible values, beliefs and attitudes that the student body may have.

\section{Thematic Discussion and Analysis}

The themes found in the data are presented in the following sections. Each theme will be introduced using quotes from one or more of the participants, referred to using pseudonyms. The quotes are both discussed and analysed within the corresponding sections. 


\subsection{Individualism}

\begin{tabular}{|c|c|}
\hline Al: & $\begin{array}{l}\text { First year sciences kind of pushed me } \\
\text { towards it [engineering].... My motivation } \\
\text { came from, like, I don't know.... He [the } \\
\text { guidance counsellor] really didn't explain } \\
\text { what engineering had to offer.... Like, I I } \\
\text { knew what kind of jobs you could get just } \\
\text { because my dad's an engineer and I knew } \\
\text { what he does. }\end{array}$ \\
\hline Vic: & $\begin{array}{l}\text { My dad's an engineer but I don't think he } \\
\text { had any influence on me wanting to be an } \\
\text { engineer. }\end{array}$ \\
\hline
\end{tabular}

Al was a first-year engineering student who had transferred from general sciences after his first year at university. He was attempting to explain why he entered general sciences in the first place and what made him decide to transfer to engineering. As he spoke, he implied that he had reached the decision largely on his own, as others, most notably his high school guidance counsellor, had offered little helpful advice. It was only at the end of the extended conversation that he chose to mention that his father was an engineer and, even then, only alluded to his influence. When asked, he did admit that his father's occupation impacted his decision, yet seemed reluctant to view it as a significant factor.

Vic's father, too, was an engineer and, even moreso than Al, Vic saw no connection between his father's profession and his decision to study engineering. Despite an obvious influence, he refused to see it.

Both $\mathrm{Al}$ and Vic display a kind of individualism. They are quite prepared to go it alone, determined to stay the course regardless of the obstacles or opposition. Any success they tend to attribute to themselves while simultaneously downplaying the influence and support of others. They therefore favour the podium model, for this is where they can stand alone and can be seen to stand alone.

Within the design environment, individualism can often be beneficial. Individualism allows one to keep projects moving when others have given up in despair, and such tenacity may be enough to encourage the doubters to rejoin the effort after they see that progress can indeed be made. However, as design invites a multidisciplinary team effort, individualism also poses some problems. Those prone to individualism are reluctant to ask for help even when they need it or could greatly benefit from it. They may fail to recognize help that has already come to their aid and credit any success as arising from their own effort, slighting other team members. They may decide to surge ahead with the project when others on the team believe that the choice of the best option requires further deliberation. The team may become disjointed.

Individualism implies a strong belief in objectivity, for, as loners, they must appeal to rules and principles rather than relationships. When a decision needs to be made, the relevant evidence is collected and analysed according to these rules and principles. In fine Baconian style, the decision logically follows. Influences from friends, nudges from colleagues, not to mention personal tastes and idiosyncrasies, are all systematically discounted. In the case of $\mathrm{Al}$, he collected the necessary data and used them to determine that he did not belong in general sciences but did belong in engineering. It was a logical decision. Admitting a predisposition to engineering due to his father's profession would have interfered with the logical process.

The objective ideal is also promoted through the science and mathematics that form the foundation in most engineering programs. Science suggests a model (rules and principles) that point to a solution of a particular problem and mathematics allows for the quantification of that solution. When these methods are properly applied, the same, correct answer is expected from all the students, regardless of personal preferences they may have. In Al's case, it is unclear whether his objective, individualistic attitude existed prior to entering the engineering program or if he developed it once within the engineering program. It is possible, however, that the engineering program supplied him with the framework to re-narrate his past so that his earlier decision process would appear logical.

The objective ideal, well suited to the individualist, is compromised in the design arena, for where multiple solutions exist, there is seldom an objective or logical way to determine which is the best. Any number of appeals to scientific or mathematical thinking are unlikely to break the impasse. As there may be many dissimilar, yet equally valid design solutions, the podium model is jeopardized. If all valid designs are invited to stand up and crowd around the podium, the podium no longer retains its value. The podium must stand separate from the crowd, not house it. Thus, design, being open-ended, can promote neither the podium model, nor the individualistic mentality. 


\subsection{Camaraderie}

Bob: There's a lot more stuff than I thought.... The people aspect. I thought I was going to come to school, do my courses and go home. But, being in engineering, it's just a lot more united. Like, you're all working towards the same goal and everybody's friendly towards everybody.

Bob was another first-year engineering student. Initially interested in computer science, he changed his mind after working for two years at a "design company" immediately after graduation from high school. His comments indicate that he assumed that engineers, and engineering students, favour individualism. Friendship and working together were assumed to be the exception rather than the rule. Where Bob's concept of engineering came from is unclear, but the design company for which he worked offered little to challenge the preconception.

The environment that Bob did find, contrary to expectations, greatly enhanced his student experience. Indeed, the friendly, helping attitude of the many of the students is a definite asset when it comes to working in the design environment with several other people on the same project. Cooperation, not competition, is what allows a design team to work together effectively.

The camaraderie in engineering reflects the historical links between engineering and the military. Bob alluded to this in the use of his terms "united" and "same goal". In the military context, the extremely trying circumstances on the battlefield demand a strong sense of unity, for the strength of an army (team) is compromised if its members are fighting among themselves.

Unfortunately, these same values present problems as well. Consider three military-inspired, ordeal features of engineering: students are given assignments that are beyond their capabilities, they receive grades that are lower than they expect and spend an inordinate amount of time on their studies [12]. The first ordeal feature, the difficulty of the assignments, is probably what forces students to seek help from one another and work together. If the assignments were unchallenging, students could, as Bob mentions, just "go home". On the negative side, and perhaps more in keeping with its military intent, if assignments become so difficult that students feel overwhelmed, they may come to view themselves as inadequate and inferior. It is at this point that the learning environment is compromised for learning becomes associated with humiliation. It is also signals the presence of the podium. Those that feel inadequate are too ashamed to stand at the podium. Indeed, the very existence of the podium is a constant reminder of their inadequacy.

In many ways, the camaraderie of engineering is the polar opposite to individualism: the former seeks outside input, the latter shuns it. They nevertheless co-exist within engineering. This co-existence is not necessarily paradoxical for opposing values are quite common in the design domain. Design for Safety, for example, often runs counter to Design for Cost, and their demands cannot always be simultaneously satisfied. The existence of opposing values is not an indication that some values must be eliminated. Rather, it speaks of the complexity of the situation. The act of elimination is an appeal to the podium, raising one set of values above another. The recognition that opposing values may be equally valid keeps the podium at bay and results in a more comprehensive design.

\subsection{Creativity}

Will: In my mind, I wouldn't consider it [creativity] a primary driving force.... I look at engineering as being a means of solving practical problems using established principles.

Will was a high school chemistry teacher. He made this comment in response to a question concerning the role of creativity in engineering design. His answer displayed a certain confidence in his understanding of engineering and he attributed this understanding largely to his membership in a council consisting of academic engineers, professional engineers and high school science teachers. The council would meet two to three times a year in an effort to address the needs of incoming engineering students. Despite the confidence he displayed and his involvement in the council, when asked if he considered himself to have a good feel for what engineering is, he replied with an unequivocal "No".

Will's comment points to a juxtaposition of "creativity" with the "established", implying a belief that, as one focuses on the established rules and principles, one tends to turn away from creativity. Conversely, if one wishes to indulge one's creative side, one tends to drift away from the establishment. 
By aligning engineering with the "established", this high school teacher implies a belief in the podium model of engineering Engineers are expected to constantly turn to the podium as they engage in their practice. At the podium are those rules and principles that they were taught at the university and to walk away from those principles is to walk away from the podium and the respect it imparts to engineers.

The rules and principles of the podium are generally associated with engineering science and mathematics. Student demonstrate their understanding of these principles through carefully constructed assignment problems. In this context, creativity plays no major role. On the other hand, creativity plays a major role in the design arena. Thus, design threatens to turn students attention away from the podium and the science and mathematics that stand there. Design is therefore not for the podium-conscious.

\subsection{Evaluation}

\section{Eva: It's based on creativity. You can't really fail something like that. \\ Ian: Given our constraints, we have a hard time rewarding creativity.}

Eva was a first-year engineering student. She made the comment as if she were speaking from the perspective of students who, unlike herself, did not like the design courses, preferring to concentrate on mathematical problems. They viewed the design courses as not really being worthy of their time. The design courses were, after all, based on creativity and creativity, they reasoned, cannot be failed. So, why bother?

Ian was a high school mathematics teacher. His comment followed after a physics teacher mentioned that high school students spend little time trying to be creative, concentrating rather on trying to get the right answer on the tests. The "constraints" that Ian mentions refer to are the evaluation methods, where examinations have a pre-determined correct answer. As creativity implies the lack of such an answer, grading becomes more difficult.

The problem with creativity, in at least in the minds of some, is related to problems of evaluation as creativity cannot be assessed using traditional methods. Some teachers, feeling constrained by an inflexible institution, may avoid assigning "creative" tasks to their students. Some students, striving to maximize the grade obtained for the amount of time spent, may consider creativity to be a waste of their time and effort.

The traditional evaluation method is based largely on a podium model. At the podium stands the correct answer, and students are expected to strive for that one answer. By shifting to problems which demand creative solutions, both the traditional evaluation method and the podium it supports are brought into question.

The evaluation methods are also linked to the kinds of knowledge students are expected to acquire. Eisner [13] talks about different types of knowledge with respect to the teaching of teachers and many of these issues correlate well with the teaching of designers. Within the traditional science and mathematics of engineering, students are expected to learn theory and then apply it to particular types of problems. The student is expected to know theoretically [13].

Design, however, is not normally viewed as a theoretical exercise; it is very much tied to practice. In the context of practice, student designers must demonstrate that they are able to make good choices. Students are evaluated on how well they justify their choices, not whether they made the "right" one. Eisner [13] talks about teaching as the "crafting of action" (p. 382) and "more like playing in a jazz quartet than following the score of a marching band" (p. 382). Designing can be seen in the same light. "Crafting" alludes to art and creativity, but at the same time may conflict with the objectivity and logic of science and mathematics. The "jazz quartet" speaks of a less than than ordered state, compared to the highly ordered, military-style marching band.

The integration of design within an engineering program requires a rethinking of the evaluation methods. One cannot simply take the methods that seem to work so well with science and mathematics and transfer them unaltered to the design domain. One cannot assess students' design choices with a model intended to determine their theoretical knowledge. To attempt to do so will only do a disservice to design, for it will only serve to highlight how design is not like science and mathematics which, for some, implies that design is inferior or lacking needed order. 


\subsection{Othering}

Jack: Things like phys ed and stuff.

Mary: It [design] is more of a physical thing which anyone has, as opposed to a mental thing which has to be earned.

Al: It's [engineering] more challenging [than sciences].... They didn't expect us to integrate.

If someone told me they were an engineering designer or something, I wouldn't really think they're an engineer. If they'd say I'm a designing engineer as opposed to I'm an engineer, I'd think they were sort of, some sort of pseudo-engineer.

Carl: Engineering seems to have a much higher level.

Jack was a Grade 12 student planning to study chemical engineering. He made frequent reference to "stuff". This particular reference arose during a discussion concerning the courses he was taking in high school and why he chose to take them. He was concentrating on what he termed "academic courses". "Stuff", in this instance, referred to what he would consider to be non-academic courses. His comment implied a disregard, maybe even contempt, for those non-academic courses, as he didn't take the time to mention what they were, except for one.

Mary was a Grade 12 student planning to study mechanical engineering. The discussion started around a question concerning the relevance of the new design courses for first-year engineering students. Mary sees design as being something relatively innate to humans and perhaps not really meriting courses where one actually attempts to teach people how to design. Based on earlier comments of her friend in the focus group, the "opposed to" that Mary refers to is mathematics. The fact that Mary chose to use the word "earned" rather than "learned" alludes to a belief in an intellectual hierarchy that is related to the effort required. Mathematics is seen to be hard work, and therefore merits additional status. Design, on the other hand, does not imply hard work. It might even be fun.

As mentioned, Al was a first-year engineering student who had transferred from general sciences.
His first comment was made as he was explaining why the transfer was necessary. It did not appear that the science of engineering was more challenging than the science of general sciences, but that engineering had a heavier concentration on mathematics. Al's intellectual status was related to the mathematical exercises he could perform, in this case, integration. His second comment questions the status that should be attributed to design. One mentions design in one's profession as a means of masking one's intellectual shortcomings. Design is for the intellectual inferior; mathematics for the intellectually superior. (Nevertheless, based on other comments, Al actually liked the design courses.)

Carl was a first-year engineering student who had transferred from communications studies and culture. $\mathrm{He}$ made his comments in partial response to $\mathrm{Al}$ (they were both in the same focus group). Engineering, according to Carl, has higher expectations of its firstyear students than sciences has of its students. Engineering took over where high school left off, but sciences repeated much of what they had already learned in high school. For this reason, engineering was at a "much higher level". It was not particularly clear whether he considered engineering sciences different from the science of general sciences, or if engineering merely covered the material more quickly. The frequent references to mathematics by several of the focus group participants implied that they felt science was incomplete without the mathematics.

The comments of all four of these students indicate that they all have a strong sense of intellectual hierarchy among the various pursuits, academic or otherwise. By creating this "us-them" dichotomy, they engaged in othering. Mathematics is consistently spoken of in positive terms (read "us"). It is the domain of talented intellectuals. Design is often spoken of in disparaging terms (read "them", or Jack's "stuff"). It is the domain of the intellectually challenged.

In the minds of some students, mathematics is clearly the stuff that engineers are made of. Anything else is just second best. Unfortunately, design falls into the second lot. This is doubly unfortunate because mathematics, moreso than science, epitomizes the podium mentality: one may take different paths to solve a mathematical problem but, in the end, all paths lead to that one, unique, correct answer. All nonconforming answers are immediately "othered". There are no exceptions. 
In sharp contrast to mathematics, design expects students to take different routes and to arrive at different destinations. In fact, identical solutions are often frowned upon. For this reason, it is highly unlikely that design will ever be able to align itself with the mathematical model. Thus, if mathematics remains the exemplar of good engineering, the metric of intellectual superiority, design has no hope of gaining any kind of prominence within engineering programs. Design will remain, at best, the domain of second-rate engineers.

\subsection{Practice}

\section{Al: $\quad$ My dad's an engineer and he asked me how to solve a triangle once with an angle and a side. [General laughter] I'm serious.}

As mentioned in a previous section, Al knew what kind of jobs engineers can expect and the kinds of things they do because his father was an engineer. By extension, Al would presumably see mathematics as playing a minor role in engineering, for his father had forgotten even a very trivial formula. Yet, his previous comments indicate he considers mathematics to be of great importance to engineers. This brings into question the role of mathematics in engineering.

Mathematics, it would appear, plays two distinct roles in engineering. First, it is a tool for practising engineers. Al's father, after all, needed it when trying to determine the area of a triangle, presumably in some real-life application. However, Al's comments indicate that mathematics does not gain its status from its power as a practical tool, for he spoke highly of mathematics with essentially no reference to practice. This reiterates the previous contention that mathematics imparts intellectual stature to engineers.

In order to maintain their intellectual status, engineers must spend a good deal of their time honing their mathematical skills. Unfortunately, the muddied waters of practice are not conducive to mathematical treatments. Hence, engineers turn to compartmentalized forms of engineering where mathematics seems to work flawlessly. In so doing, they turn mathematics from a tool of practice to one of theory. It is basically a physics or Einsteinian model, where theory is exalted over practice, particularly when that theory in encapsulated in mathematical formulas, e.g., $e=m c^{2}$.
Within engineering, design is typically reserved exclusively for the arena of practice. Design is all about building a better widget. Although one may apply theory to the development of the widget and see its implications, it is not the place where one actually learns the theory.

Strictly viewed as practice and void of any theory of its own, design finds itself devalued, at the far end of the spectrum. At the other end of the spectrum lies mathematics, bestowing intellectual stature, embodying theory and reputed to be difficult. Thus, being at opposite ends of the spectrum, as mathematics is difficult, so design must be easy. As mathematics is prestigious, so design must be ordinary. Furthermore, design is taught according to the old British apprenticeship model, not the French theoretical model. Design cannot produce podium material, for practice only leads to more practice [14].

If design is to gain respect in traditional engineering programs, it must break the practice-practice circle. In this case, design would be wise to look to mathematics for guidance. Design, like mathematics, has a practical side but design, like mathematics, also has a theoretical side. These theories should be presented to students as they are worth knowing. Some of these theories will impact the students' design work directly. Some will impact the students' design work indirectly as they open their minds to new ways of thinking and new ways of knowing.

\section{Concluding Remarks}

The integration of a significant design experience into engineering programs, traditionally based on science and mathematics, presents pedagogical challenges. If design is to have a meaningful place in the program, the way that science and mathematics are taught must change. The change is necessary as science/mathematics and design embody two different paradigms.

The paradigmatic differences can be explored using the metaphor of the podium. The podium speaks to a hierarchical structure that seeks to separate the winners from the losers, those that succeed from those that fail. The winners, few in number, rise to the podium and look down on the masses below.

Science and mathematics, as traditionally taught to engineering students, generally supports the podium model. The rules and principles of science and mathematics represent the highest possible standards. Science and mathematics thus sit at the podium. 
The mandate to include open-ended design components in accredited engineering programs brings the appropriateness of the podium model into question. The values promoted by the podium often run counter to those of design. Thus, the promotion of the podium often leads to a devaluation of design.

The manifestation of the podium and its negative effect on design can be seen in themes derived from case study data of first-year and prospective engineering students, as well as high school teachers. These themes include the individualistic and othering mentalities, creativity, evaluation methods, camaraderie and theory/practice distinctions.

Many of those interviewed showed a tendency toward individualism or to othering. Individualism assumes that one can do it on one's own, thereby rising to the podium and standing out of the crowd. Within the design arena, this may lead to ignoring the input of others and downplaying their assistance. Othering sets up an "us-them" dichotomy, with the "us" sitting at the podium. In the act of exalting science and mathematics, those that "other" risk excluding pertinent, but "unscientific", perspectives from their design activities.

The camaraderie created in engineering can be of great benefit to working on design teams. Unfortunately, the feature of engineering programs that helps develop this camaraderie, namely the difficulty of the assignments, may also result in feelings of inadequacy. These feelings allude to the existence of a podium reserved for those who have mastered the material. When assignments become overwhelming, the podium looms particularly large and learning is associated with humiliation.

The high esteem bestowed on mathematics by engineers often has a negative impact on the respectability of design. Mathematics seeks a single, correct answer, regardless of the solution path. Design solutions, though typically along different paths, seldom lead to the same answer. The problem is compounded as the ambiguity of the design solutions leads to evaluation problems. Mathematics also places a high premium on theory. Design, on the other hand, speaks of practice. Hence, as mathematics is difficult, so must design be easy. Mathematics puts the engineer on the podium; design does not. The devaluation of design also tends to lead to a devaluation of creativity.

By removing the podium model from the engineering program, the hegemony of science and mathematics is broken. Science and mathematics are placed on equal footing with design and other "nonscientific" engineering concerns. The removal of the podium must be accompanied by a reconception of design. Design can no longer remain the domain of practice alone, but must make theoretical considerations an integral part of its study. The point is not only to build a better widget, but to better educate an engineer.

\section{References}

[1] T. Shinn, L'École Polytechnique, Presse de la Fondation Nationale des Sciences Politiques, Paris, 1980.

[2] L.P. Grayson, The Making of an Engineer, Wiley, New York, 1993.

[3] F.E. Griggs Jr., "Amos Eaton was right”, Journal of Professional Issues in Engineering Education and Practice, 123, pp. 30-34, 1997.

[4] G. Pahl and W. Beitz, Engineering Design: A Systematic Approach, trans. by Ken Wallace, Lucienne Blessing and Frank Bauert, Springer-Verlag, London, 1996.

[5] CBC News, "Ottawa students face expulsion over ethics paper", http://www.cbc.ca/stories/2002/03/26/cheat020326, 2002 (accessed March 17, 2006).

[6] Canadian Council of Professional Engineers, Accreditation Criteria and Procedures, http://www.ccpe.ca/e/files/report_ceab.pdf, 2005 (accessed May 16, 2006)

[7] Bell, Lee Anne "The gifted woman as impostor", Advanced Development Journal, Vol. 2, pp. 55-64, 1990.

[8] Barrie Thorne, "The ins and outs of othering", in Barry Glassner and Rosanna Hertz (eds.), Our Studies, Ourselves: Sociologists' Lives and Work, Oxford University Press, New York, 2003, pp. 162-173.

[9] T.A. van Dijk, "Principles of Critical Discourse Analysis", Discourse and Society, pp. 249-283, 1993.

[10] Robert Yin, Case Study Research, Sage Publications, Beverly Hills, CA, 1984.

[11] Sharon Vaughn, Jeanne Shay Schumm and Jane Singaub, Focus Group Interviews in Education and Psychology, Routledge, London, 1996.

[12] J.B. O'Neal, "Engineering education as an ordeal and its relationship to women in engineering", $A S E E$ Annual Conference Proceedings, ASEE, Location, pp. 1008-1101 [sic], 1994.

[13] Elliot W. Eisner, "From episteme to phronesis to artistry in the study and improvement of teaching", Teaching and Teacher Education, Vol. 18, pp. 375385, 2002.

[14] Deborah Britzman, Practice Makes Practic: A Critical Study of Learning to Teach, State University of New York Press, Albany, New York, 1991. 